\title{
Primer Frekans Kontrolünde Batarya Enerji Depolama Sistemleri Kullanımının Analizi*
}

\author{
Ercüment Özdemirci ${ }^{1 * *}$ ve Mehmet Cebeci ${ }^{2}$ \\ ${ }^{1}$ Elektrik-Elektronik Mühendisliği/ Fen Bilimleri Enstitüsü, Fırat Üniversitesi, Elazı̆̆, Türkiye \\ ${ }^{2}$ Elektrik-Elektronik Mühendisliği/ Fen Bilimleri Enstitüsü, Fırat Üniversitesi, Elazığ, Türkiye
}

(Konferans Tarihi: 5-7 Mart 2020)

(DOI:10.31590/ejosat.araconf37)

\begin{abstract}
ATIF/REFERENCE: Özdemirci, E \& Cebeci, M. (2020). Primer Frekans Kontrolünde Batarya Enerji Depolama Sistemleri Kullanımının Analizi. Avrupa Bilim ve Teknoloji Dergisi, (Özel Say1), 292-297.

$\ddot{O} \mathbf{z}$

Güç sistemlerinde artan yenilenebilir üretim, düşen sistem ataleti ve buna bağlı olarak değişen sistem frekans davranışı olarak ortaya çıkmaktadır. Bu probleme depolama sistemlerinin frekans kontrolünde kullanımı ile önemli bir çözüm oluşturulabilmektedir. Batarya depolama sistemlerinin hızlı tepki verme özelliği, frekans kontrolünde en yaygın kullanılan teknoloji olmasını sağlamaktadır. Primer frekans kontrolü sistem frekansının düşmesine veya yükselmesine tepki olarak ünite aktif güç çıkışının otomatik artırılması veya düşürülmesi yoluyla sistem frekansının yeni bir denge noktasına getirilmesi olarak tanımlanır. Bu çalışmada bataryanın iletim sisteminde primer frekans kontrolünde kullanılması halinde sistem frekans kontrolü performansına katkısı Matlab/Simulink ortamında analiz edilmiştir. Yapılan analizlerde Türkiye güç sisteminde işletmede olan santrallerin bir bölümüne ait hız regülatörü ve türbin modelleri kullanılmıştır. Batarya kullanımı ile birlikte maksimum frekans sapmasının önemli oranda azaldığı benzetim sonuçları ile gösterilmiştir.
\end{abstract}

Anahtar Kelimeler:Primer Frekans Kontrolü, Batarya Enerji Depolama Sistemleri.

\section{An Analysis of Battery Energy Storage Systems for Primary Frequency Control}

\begin{abstract}
Increased renewable production in power systems cause falling system inertia and consequently changing system frequency behavior. An important solution can be created to this problem via participation of storage systems in frequency control. The fast response facility of battery storage systems makes it the most widely used technology in frequency control. Primary frequency control is defined as setting the system frequency to a new balance point by automatically increasing or decreasing the generation unit active power output in response to the falling or rising of the system frequency. In this study, the batteries effect to the frequency control performance was analyzed through Matlab / Simulink. Speed regulators and turbine models of some part of power plants in Turkish power system were used in the analysis. Simulation results have shown that the maximum frequency deviation decreases significantly with support of the battery.
\end{abstract}

Keywords: Primary Frequency Control, Battery Energy Storage Systems

\footnotetext{
${ }^{*}$ Bu makale International Conference on Access to Recent Advances in Engineering and Digitalization (ARACONF 2020) de sunulmuştur.

${ }^{* *}$ Sorumlu Yazar:Fırat Üniversitesi, Mühendislik Fakültesi, Elektrik-ElektronikBölümü, Elazı̆̆, Türkiye, ORCID: 0000-0000-0000-0000, eozdemirci@hotmail.com
} 


\section{Giriş}

Elektrik enerjisinin kalitesini; limitler dahilinde frekans, limitler dahilinde gerilim ve kesintisiz enerji olmak üzere üç temel bileşen belirlemektedir. Frekans limitleri, üretim-tüketim dengesinin oluşturulması ile sağlanabilmektedir. Yenilenebilir üretim kaynaklarının toplam üretimdeki payı her geçen gün artmakta olup, buna bağlı olarak elektrik sisteminin kalite limitleri dahilinde işletilmesi, her geçen gün zorlaşmaktadır. Konvansiyonel güç sistemlerinde kontrol dişı değişkenlik yalnızca tüketim tarafında iken, yenilenebilir üretim kaynakları ile birlikte kontrol dışı değişkenlik kavramı üretim tarafı için de söz konusu olmaktadır. Bu durumda sistem işletmeciliği çok daha karmaşık bir yapı halini almaktadır. Sistem işletmeciliğinde yenilenebilir enerji kaynaklarının getirdiği olumsuzluklara karşın; teknolojik çeşitliliği artan depolama sistemleri; elektrik sisteminde arz güvenliği, enerji kalitesi ve enerji ekonomisi ana başlıkları altındaki çeşitli uygulamalar için olumlu katkılar sunmaktadır. Önümüzdeki süreçte depolama sistemleri, enerjideki değişimi destekleyen en önemli araç olacaktır.

Bataryalar, pompa depolamalı HES'lerden sonra en çok kullanılan ikinci teknolojidir. Dünya genelinde bataryaların toplam kurulu gücü 1,9 GW seviyesine ulaşmıştır [1]. Depolama sistemleri yan hizmetler piyasasında, özellikle primer frekans kontrolünde her geçen gün daha fazla kullanım alanı bulmaktadır. Frekans normal olarak $50 \mathrm{~Hz}$ etrafinda sürekli bir salınım gösterir, ters yönlü ani bir frekans sapması durumunda konvansiyonel bir elektrik santrali zamanında güç çıkışını değiştiremeyebilir. Bu durum, santralin bir süre boyunca istenilen primer frekans kontrol davranışının tam tersi tepki vermesi anlamına gelmektedir. Batarya depolama sistemlerinde ise bu gecikmeler pratik olarak mevcut değildir.

Elektrik Piyasasına satış yapan üretim santralleri, frekans kontrolünü etkinleştirmek için her zaman belirli bir Güç Rezervini elinde bulundurmalıdır. Enerji satışı ile rezerv güç arasında optimizasyon sağlamak her zaman mümkün olmayabilir. Bunun yerine bataryalar yalnızca yan hizmet servisleri için kullanılırlar.Primer frekans kontrolü yerel ve otomatik olarak etkinleştirilmiş bir hizmettir ve sekonder frekans kontrolü gibi, merkezi bir sinyal ve haberleşme sistemi kurulmasını gerektirmez. Evlerde kullanılan küçük bataryalar gibi dağıtılmış kaynaklar teorik olarak erişim noktasındaki frekansı referans olarak kullanılarak kontrol mekanizmasına katılabilirler [2].Bu çalışmada, batarya depolama sisteminin primer frekans kontrolünde kullanımı incelenmiş, sistem frekans performansına etkisi benzetim çalışmaları ile ortaya konulmuştur.

\section{Materyal ve Metot}

\subsection{Batarya Depolama Sistemlerinin Frekans Kontrolünde Kullanımı}

Şebekenin bir anma frekansında (örneğin, Avrupa Şebekesi için $50 \mathrm{~Hz}$ ) dengelenmesi, birçok farklı üretim kaynağının değişken yüklere karşı yönetilmesini gerektirir. Bu durum, yenilenebilir enerji kaynaklarının miktarındaki artış ve sisteme atalet sağlayan geleneksel üretim kaynaklarının azalması ile gittikçe zorlaşmaktadır. Bu sorunun üstesinden gelmek için, İngiltere'deki ana iletim şebekesi operatörü National Grid, sistem frekansını normal koşullarda 50 Hz'e daha yakın tutmayı amaçlayan.

Geliştirilmiş Frekans Cevabı (GFC, Enhanced Frequency Response-EFR) adı verilen yeni bir hızlı frekans hizmeti sunmaktadır. Böyle bir hizmeti şebekeye sunmak için Batarya Enerji Depolama Sistemi (BEDS, Battery Energy Storage System-BESS) ideal bir adaydir.

\begin{tabular}{lll}
\hline Ref.Noktası & Set-1 $(\mathbf{H z})$ & Set-2 $(\mathrm{Hz})$ \\
\hline A & 49.5 & 49.5 \\
B & 49.75 & 49.75 \\
C & 49.95 & 49.985 \\
D & 50.05 & 50.015 \\
E & 50.25 & 50.25 \\
F & 50.5 & 50.5 \\
\hline
\end{tabular}

\begin{tabular}{lll}
\hline Ref.Noktası & Set-1 (\%) & Set-2(\%) \\
\hline $\mathrm{t}$ & 100 & 100 \\
$\mathrm{u}$ & 44.44444 & 48.45361 \\
$\mathrm{v}$ & 9 & 9 \\
$\mathrm{w}$ & 0 & 0 \\
$\mathrm{x}$ & -9 & -9 \\
$\mathrm{y}$ & -44.44444 & -48.45361 \\
$\mathrm{z}$ & -100 & -100 \\
\hline \hline
\end{tabular}

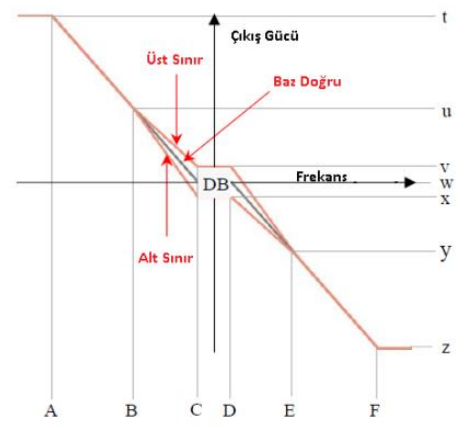

Şekil-1 Ingiltere'de uygulanan gelişmiş frekans kontrolü hizmeti sınır değerleri [3]

İngiltere'de, şebeke frekans desteği sağlamak için uygun sınırlı sayıda kurulu batarya depolama sistemi mevcuttur. 2013'te, İngiltere'nin Willenhall Enerji Depolama Sistemi olarak adlandırılan ilk şebeke bağlantılı lityum titanyum BEDS, büyük ölçekli bataryalarla ilgili araştırma yapmak ve şebeke yan hizmetleri araştırması için bir platform oluşturmak amacıyla Sheffield Üniversitesi tarafından işletmeye alınmıştır. GFC frekans sapmasının 1 saniyesi içinde \%100 aktif güç sağlayabilen yeni bir yan hizmet sunmaktadır National Grid, 2016 yılı bir GFC şartnamesi hazırlamıştır [3]. 
Şekil-2'de, 30 dakika boyunca sağlanan primer frekans kontrolüne ilişkin batarya sistemlerinin, Almanya'da uygulanan $\mathrm{MWh} / \mathrm{MW}$ oranına göre çalışma aralığı grafiği verilmiştir. Örneğin 2,5 MWh depolama kapasitesine sahip bir batarya $1 \mathrm{MW}$ Primer rezerv gücüne sahip ise $\% 20-\% 80$ şarj aralı̆̆ında çalışması gerekmektedir.

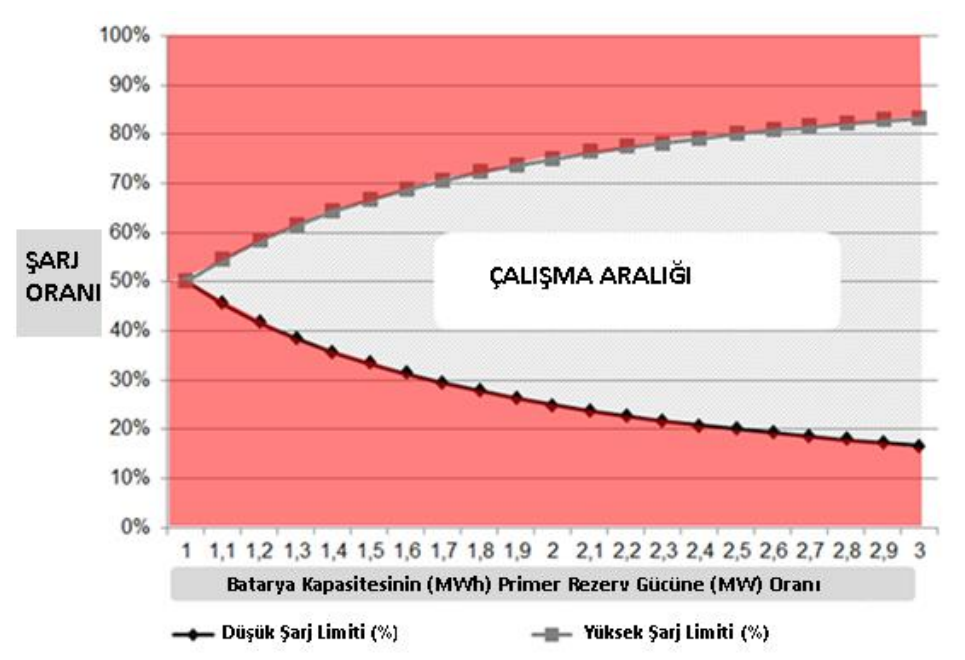

Şekil-2 Almanya'da uygulanan batarya çalıșma sınır değerleri [4]

Sisteme güç elektroniği kompanentleri üzerinden bağlı rüzgar ve güneş üretiminin artışı ile eş zamanlı kömür, doğal gaz ve petrol yakıtlı elektrik santrallerinin üretimi düşmektedir. Kaynak dağılımı değiştikçe, sistem ataleti azalmakta ve bu durum acil durum olaylarına daha duyarlı olabilecek bir elektrik şebekesi oluşturmaktadır. Düşük ataletli bir ortamda, frekans değişim hızı artacaktır. Bu da şebeke elemanlarının frekans düşüşünü durdurmak ve şebekeyi kararlı kılmak için daha hızlı cevap vermelerini gerektirmektedir. Düşük ataletli bir ortamda, sistem ataleti ve konvansiyonel santrallerin governer fonksiyonları ile primer frekans tepkisi, sistem kararlılığını korumak için yetersiz kalabilir. Güney Avustralya'da 2016 yılında meydana gelen sistem oturması, büyük çaplı düşük ataletli güç sistemlerinin bugün hali hazırda çalışmakta olduğunu ve bu tür riskleri azaltmak için sistem işletimi, kontrolü ve korumalarında farklı bir yaklaşım gerektiğini göstermektedir[4].

Yenilenebilir oranı arttıkça, sistem ataleti ve governer tepkisi azalacaktır. Bu durumda geleneksel olmayan kaynaklardan frekans tepkisi tedarik edecek yeni piyasa yapıları ve mekanizmaları gerekecektir. Bu mekanizmalar rüzgar ve güneş kaynakları, enerji depolaması ve talep tarafı tepkisi olarak sıralanır. İrlanda, İngiltere, Yeni Zelanda, Hawaii, Texas (ERCOT-Electric Reliability Council of Texas) ve Avustralya'da GFC pazarları ve ödeme mekanizmaları şekillenmektedir [4].

\subsection{Güç Sistemi ve Batarya Modellemesi}

Türbin-generatör sisteminin Şekil-3'de yer alan basite indirgenmiş blok diyagramı generatörün hızı ile generatöre uygulanan elektriksel ve mekanik güç arasındaki transfer fonksiyonunu göstermektedir.

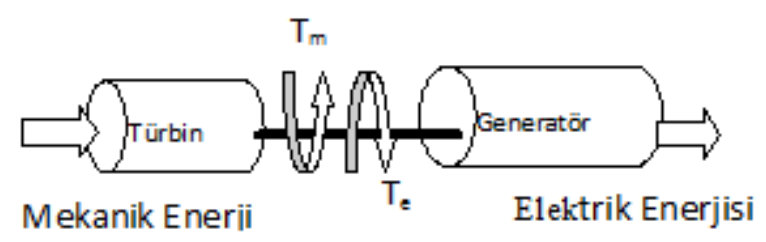

Şekil-3 Türbin-generatör sistemi fiziksel modeli

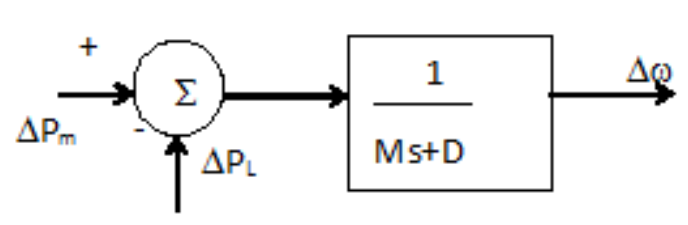

Şekil-4 Dönen kütle ve yükün indirgenmiş blok diyagramı

$$
\begin{aligned}
& P_{a}=P_{m}-P_{e}=M \frac{d \omega}{d t} \\
& \frac{d \omega}{d t}=\frac{1}{M}\left(P_{m}-P_{e}\right)
\end{aligned}
$$


Burada Pa ivme gücü, Pm mekanik güç, Pe elektriksel güç, $\omega$ açısal hız, M ise makinanın açısal momentumudur.

$$
\Delta \mathrm{P}_{\mathrm{e}}=\Delta \mathrm{P}_{\mathrm{L}}+\mathrm{D} \Delta \omega
$$

Elektriksel güç sisteminde yükler değişik elektriksel aygıtlardan oluşur ve buna bağlı olarak farklı yük karakteristikleri mevcuttur. Elektriksel yüklerin önemli bir kısmını fanlar ve pompalar gibi frekansa bağlı olarak gücü değişen motor yükleri oluşturduğundan, frekans değişikliğinin sistemin çektiği toplam yükü nasıl etkilediğinin modellenmesi çok önemlidir. Frekans değişikliğine bağlı olarak yükün değişmesi aşağıdaki gibi modellenir:

Yük sönüm sabiti D, yükteki yüzde değişimin frekanstaki yüzde değişime oranı olarak ifade edilir. Örneğin frekanstaki \%2 değişim için, yük \%1 değişirse, $\mathrm{D}=2 / 1=2$ olarak hesaplanır. $\Delta \mathrm{Pe}$ elektriksel güçteki net değişim, $\Delta \mathrm{PL}$ ise frekansa duyarsız yük değişimidir. Dönen Kütle ve yükün indirgenmiş modeli Şekil-4'de verilmektedir.Şekil-4'deki blok diyagramında verilen döner kütleyük modelinde $1 /(\mathrm{Ms}+\mathrm{D})$ ifadesi yerine $\mathrm{Kp} /(1+\mathrm{sTp})$ ifadesi kullanılabilir [5] .

$$
\mathrm{K}_{\mathrm{P}}=\frac{1}{\mathrm{D}} \quad \text { ve } \quad \mathrm{T}_{\mathrm{P}}=\frac{\mathrm{M}}{\mathrm{D}} \quad \text { olur. }
$$

Yük-frekans kontrolünde aktif rol oynayan hız regülatörü, türbin ve yükten oluşan ikincil regülasyonun olmadığı tek alanlı güç sistemi modeli Şekil-5'de görüldüğü gibidir. Burada R regülasyon sabiti, T ise hız regülatörü Türbin zaman sabiteleridir.

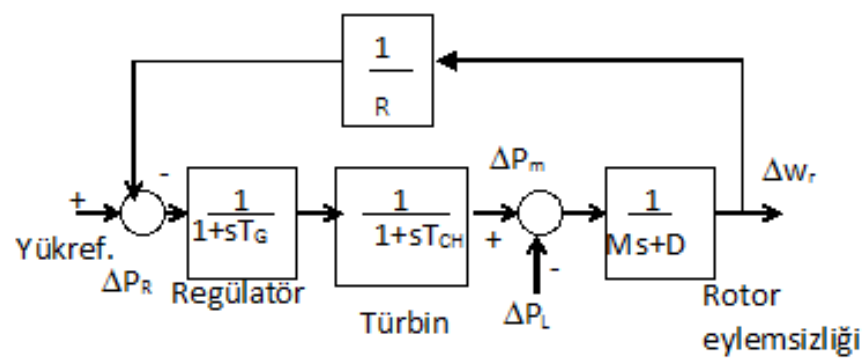

Şekil-5 İkincil regülasyonun olmadı̆̆ı durumda tek alanlı güç sistemi blok diyagramı

Güç sistemi ile entegre batarya depolama sisteminin şematik gösterimi Şekil-6'da verilmektedir. Uygun kontrolör tasarımı ile dönüştürücü ve batarya kaskat bağlanmaktadır. Ayrıca $\mathrm{Y} / \Delta-\mathrm{Y}$ transformatör üzerinden sistemin şebeke bağlantısı gerçekleştirilmektedir [6].

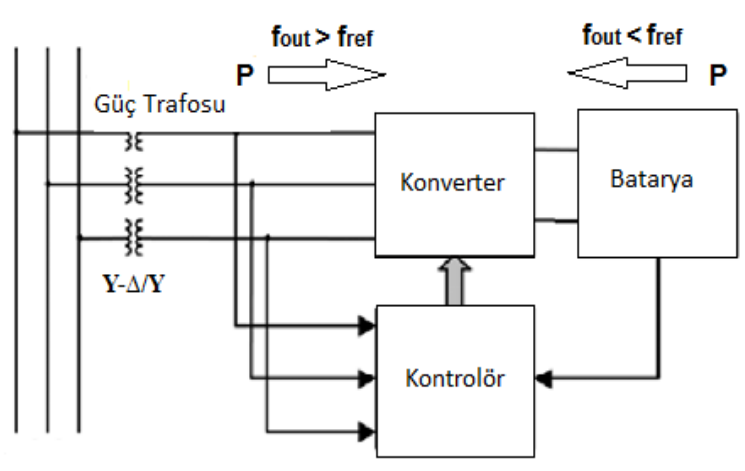

Şekil-6 Batarya Depolama Sistemi Şebeke Bă̆lantısı [6]

Batarya depolama sistemleri, dönüştürücünün mevcudiyeti ve elektro-kimyasal olayların doğası sayesinde çok hızlı ve kolay regüle edilebilir bir ünitedir. Bu nedenle Pimer Frekans Kontrolünde konvansiyonel üretim tesislerindeki \%5 hız regülatörü karakteristiğine göre çok daha iyi performans gösteren \%4'lük değer kullanılabilir. Konvansiyonel santrallerde Pmax değeri ile Pnom arasındaki 
\%5'lik primer frekans kontrolü için kullanılırken bataryada bu değer \%100'dür. Bu nedenle batarya için yeni eşdeğer hız-eğim karakteristiği hesaplaması zorunludur. Şekil-7'de batarya için eşdeğer hız-eğim karakteristiği tablosu verilmektedir [7].

\begin{tabular}{cl}
\hline Generatör [\%] & Batarya[\%] \\
\hline 5 & 0.25 \\
4 & 0.2 \\
3 & 0.15 \\
2 & 0.1 \\
\hline
\end{tabular}

Şekil-7 Batarya Eşdeğer Hiz-Ĕ̆im Karakteristiği [7]

Batarya depolama sisteminin dinamik karakteristiği basit ve çok hızlı olması nedeniyle batarya tepki modeli birinci dereceden zaman gecikmeli fonksiyon kullanılabilir [8].

\section{Araştırma Sonuçları ve Tartışma}

\subsection{Benzetim Sonuçları}

Benzetim çalışması Matlab/Simulink ortamında yapılmıştır. Tablo 1 ile Tablo 2'de yer alan termik ve hidrolik santral üniteleri çalışmaya dahil edilmiştir. Türkiye elektrik güç sistemi döner kütle yük modeli oluşturulurken literatürde yer alan bilgiler kullanılmış, $\mathrm{Kp}=120 \mathrm{~Hz} / \mathrm{MWpu}, \mathrm{Tp}=20$ s olarak seçilmiştir [9].

Tablo 1. Termik Santral Ünite Güçleri

\begin{tabular}{|c|c|c|}
\hline $\begin{array}{c}\text { Santral } \\
\text { Adı }\end{array}$ & $\begin{array}{c}\text { Ünite } \\
\text { No }\end{array}$ & $\begin{array}{c}\text { GüG } \\
\text { (WW) }\end{array}$ \\
\hline Ambarı FueloI & $1-5$ & $5 \times 114$ \\
\hline Ambarlı Doğalgaz & $\begin{array}{c}\text { A1,A2,A3 } \\
\text { B1,B2,B3 } \\
\text { C1,C2,C3 }\end{array}$ & $\mathbf{6 \times 1 3 8 , 8 + 3 \times 1 7 2 , 8}$ \\
\hline Bursa Doğalgaz & $\begin{array}{c}\text { A1,A2,A3 } \\
\text { B1,B2,B3 }\end{array}$ & $4 \times 239+2 \times 237,5$ \\
\hline Çayınan & $1-4$ & $4 \times 160$ \\
\hline Colakoğlu & A1,A2,A3 & $2 \times 136+170$ \\
\hline Elbistan & $1-4$ & $4 \times 344$ \\
\hline Kangal & $1-3$ & $3 \times 160$ \\
\hline Kemerkōy & $1-3$ & $3 \times 210$ \\
\hline Seyitōmer & $1-2$ & $2 \times 153$ \\
\hline Seyitōmer & $3-4$ & $2 \times 159,8$ \\
\hline Tunçbilek & $5-6$ & $2 \times 159,8$ \\
\hline Yatağan & $1-3$ & $3 \times 210$ \\
\hline Yenikōy & $1-2$ & $2 \times 210$ \\
\hline & & \\
\hline
\end{tabular}

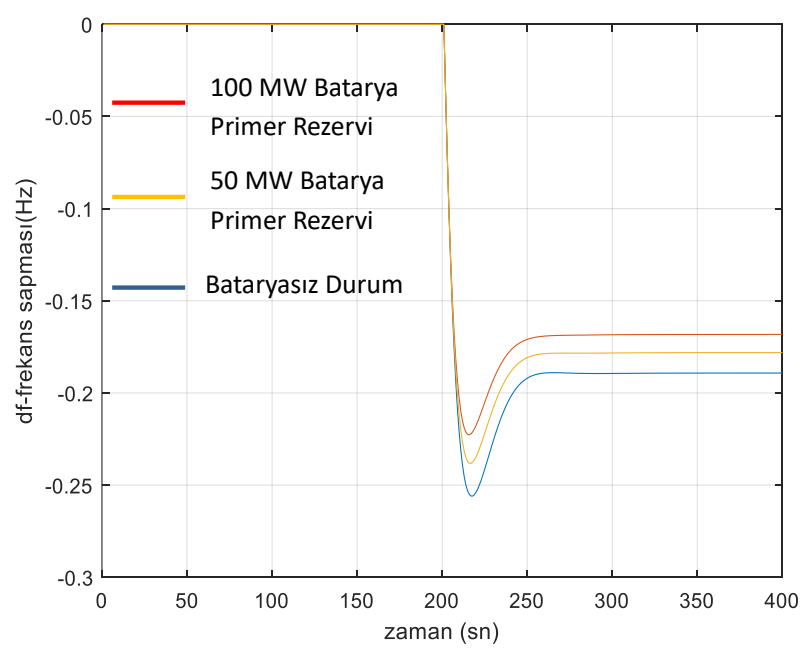

Şekil-8 600 MW üretim kaybı için frekans sapması
Tablo 2. Hidrolik Santral Ünite Gücleri

\begin{tabular}{|c|c|c|}
\hline $\begin{array}{c}\text { Santral } \\
\text { Adı }\end{array}$ & $\begin{array}{c}\text { Ünite } \\
\text { No }\end{array}$ & $\begin{array}{c}\text { Ünite } \\
\text { Gücü (MW) }\end{array}$ \\
\hline Altnkaya & $1-4$ & $4 \times 175$ \\
\hline Atatūrk & $1-8$ & $8 \times 300$ \\
\hline Birecik & $1-6$ & $6 \times 125$ \\
\hline Gökçekaya & $1-4$ & $4 \times 93,8$ \\
\hline H.Uğunlu & $1-4$ & $4 \times 125$ \\
\hline Karakaya & $1-6$ & $6 \times 300$ \\
\hline Keban & $1-4$ & $4 \times 157,5$ \\
\hline Keban & $5-8$ & $4 \times 165$ \\
\hline Oymapinar & $1-4$ & $4 \times 150$ \\
\hline
\end{tabular}

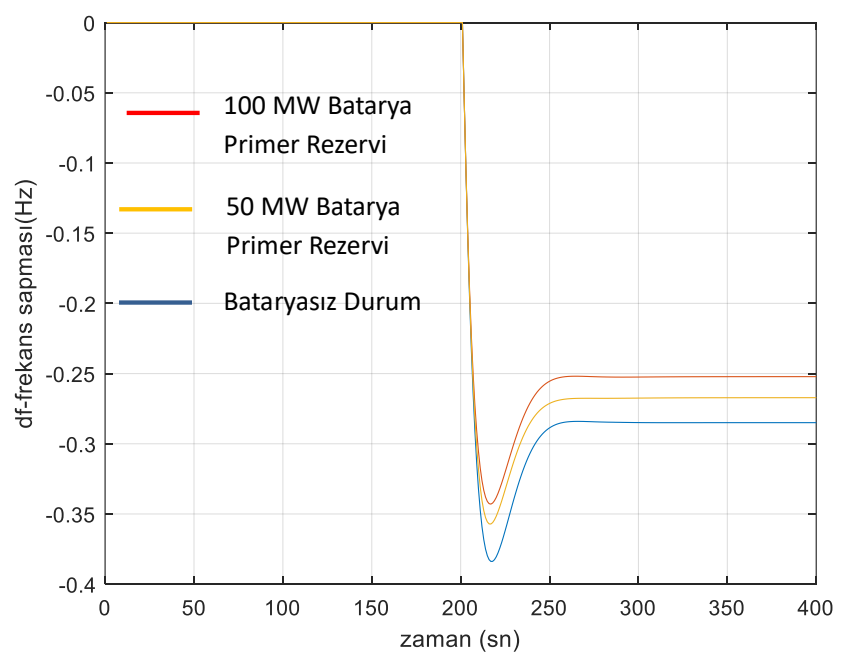

Şekil-9 900 MW üretim kaybı için frekans sapması 
Batarya tepki modeli olarak birinci dereceden zaman gecikmeli $(0.03 \mathrm{~s})$ fonksiyon kullanılmıştır.Sistem $15190 \mathrm{MW}$ üretim değerinde dengede çalışırken, $600 \mathrm{MW}$ ve $900 \mathrm{MW}$ üretimin devre harici olması durumları analiz edilmiştir. Analizler batarya desteğinin olmadığı durum, $50 \mathrm{MW}$ ve $100 \mathrm{MW}$ batarya primer rezervi durumları için yinelenmiştir.

$600 \mathrm{MW}$ ani üretim kaybında bataryanın devrede olmaması, $50 \mathrm{MW}$ ve $100 \mathrm{MW}$ batarya primer rezervi durumları için sırasıyla $0.26,0.24$ ve $0.22 \mathrm{~Hz}$ frekans sapması oluşmuştur. $900 \mathrm{MW}$ ani üretim kaybında ise bataryanın devrede olmaması, $50 \mathrm{MW}$ ve 100 MW batarya primer rezervi durumları için sırasıyla $0.38,0.36$ ve $0.34 \mathrm{~Hz}$ frekans sapması oluşmuştur.

\section{Sonuç}

Batarya sistemlerinin hızlı tepki verme özelliği, frekans kontrolünde en yaygın kullanılan teknoloji olmasını sağlamaktadır. Yenilenebilir oranı arttıkça, sistem ataleti azalacaktır. Bu durumda geleneksel olmayan kaynaklardan frekans tepkisi tedarik edecek yeni piyasa yapıları ve mekanizmaları gerekecektir. Bu mekanizmalar rüzgar ve güneş kaynakları, enerji depolaması ve talep tarafı tepkisi olarak sıralanır. Bu çalışmada batarya depolama sisteminin primer frekans kontrolüne katkısı analiz sonuçlarına yansıtılmıştır. Herhangi bir ani üretim kaybında sistem için en kritik husus maksimum frekans sapması olup, batarya depolama sistemi primer kontrol rezerv miktarı artıkça bu sapma değeri önemli oranda azalmaktadır. Batarya tarafından primer frekans kontrol rezervleri sağlanırken bataryalar için ana zorluk, şarj durumu yönetimidir. Dolayısıyla primer frekans kontrolüne katılan bataryanın elektrik piyasası yan hizmetler mekanizması fiili verileri dahilinde şarj durumu yönetimi ve optimizasyonu yapılacak çalışmaların temelini oluşturacaktır.

\section{Kaynakça}

[1] «EPRI-DOE Handbook of Energy Storage for Transmission \& Distribution Applications,» EPRI, Washington, 2003.

[2] F. Arrigo, Primary Frequency Control by Energy Storage System: a Fourier Transform procedure for the dynamic analysis of theGrid, Milano: PolitecnicoMilano , 2016.

[3] B. Gundogu, S. Nejad, D. Gladwin ve D. Stone, A Battery Energy Management Strategy for UK EnhancedFrequencyResponse, IEEE, pp. 26-31, 2017.

[4] FCR Storage Battery Capacity Requirements, German TSO's, 2017.

[5] Faried S.O, Demeter E., Teaching Load Frequency Control Using Matlab and Simulink, Int. J. Electrical Enging. Education, Vol 35, pp 155-1611998,

[6] Pradipkumar Prajapati, Ashok Parmar ,Multi-area Load Frequency Control by VariousConventional Controller using Battery Energy, 2016 IEEE

[7] Francesco Arrigo, Primary Frequency Control by EnergyStorage System: a Fourier Transformprocedure for the dynamic analysis of the Grid, Master Thesis 2016

[8] H.-J. Moona, A.-Y. Yuna, E.-S. Kimb ve S.-I. Moona, ,An Analysis of Energy Storage Systems for Primary Frequency Control of Power Systems in South Korea, Energy Procedia, 107, pp. 116121, 2017.

[9] Ercüment Özdemirci, Mehmet Özdemir “Load Frequency Control that is Formed Fuzzy PI Controller”, TAINN,2001 